\title{
QUESTÕES PRELIMINARES ACERCA DA REPRESENTAÇÃO POLÍTICA NO BRASIL: A PERCEPÇÃO DOS ELEITORES A PARTIR DOS DADOS DO ESEB DE 2002 A 2014
}

\author{
PRELIMINARY ISSUES ABOUT POLITICAL \\ REPRESENTATION IN BRAZIL: THE PERCEPTION \\ OF THE VOTERS FROM ESEB'S DATABASE FROM \\ 2002 TO 2014
}

Soraia Marcelino Vieira*

\begin{abstract}
Resumo: A representação é um importante elemento para a democracia. Atualmente muito se tem debatido sobre as questões referentes a este tema. Neste artigo enfatiza-se a representação partidária como importante componente para a democracia. Busca-se observar como os brasileiros têm percebido a representação, se consideram que há algum partido que os representa, se há algum partido que gostam e como essas duas variáveis se relacionam entre si e com as variáveis sexo e escolaridade. Para isto utiliza-se dos dados do ESEB (2002, 2006, 2010 e 2014). Os métodos privilegiados são a revisão bibliográfica e a estatística descritiva. Os dados sinalizam a variação nas percepções dos entrevistados às quais poderão ser investigadas mais profundamente incorporando variáveis contextuais na análise.
\end{abstract}

Palavras-chave: Representação. Partidos Políticos. Percepção. Brasil.

\begin{abstract}
Representation is an important element for democracy. Much has been debated recently on issues related to this topic. This article emphasizes party representation as an important component for the democratic process. It aims to observe how Brazilians have perceived the representation, if they consider any party a representation of their ideas and needs, if there is a party that they like and how these two variables are related to each other and with other two variables: gender and schooling. For this purpose, the ESEB (Estudo Eleitoral Brasileiro) data during the years of 2002, 2006, 2010 and 2014 was used. The chosen methods were bibliographical review and descriptive statistics. The data indicates the variation in the perception of the interviewees, which can be investigated more deeply incorporating contextual variables in the given analysis.
\end{abstract}

Keywords: Representation. Political parties. Perception, Brazil.

* Professora adjunta da Universidade Federal Fluminense. E-mail: soraiamv@id.uff .br 


\section{Introdução}

A representação política é um tema que tem estado há algum tempo no debate político. Os problemas acerca do alcance e da limitação desse modelo têm sido levantados por pesquisadores há mais de 50 anos. No modelo experimentado por diversas democracias contemporâneas, a representação desponta como a melhor alternativa para intermediação de interesses e construção de uma agenda de políticas públicas.

Uma importante questão a ser considerada é: como fazer com que o interesse público seja maior que os interesses privados? A representação desponta como a opção mais apropriada para que o interesse público realmente seja o privilegiado. Nesse sentido, é importante destacar a importância dos agentes intermediadores dos interesses na construção de uma agenda pública. Os partidos políticos despontam, então, como atores-chave nesse processo de intermediação entre demandas e interesses privados e o poder público.

A existência de diferentes partidos faz-se importante, uma vez que cada um deles levantaria demandas de certos interesses específicos, ou seja, cada partido com sua ideologia representaria um grupo social. Contudo, muito se tem discutido a respeito desse papel intermediador dos partidos políticos. Um importante debate contemporâneo está relacionado à ideia de crise desses atores políticos, crise essa que se refletiria, especialmente, em seu papel de representação.

A partir dessa breve introdução, este artigo busca discutir a temática da representação, analisando a problemática no contexto brasileiro recente. O objetivo é observar e descrever a percepção dos brasileiros no que tange à representação nos últimos 16 anos, período ao longo do qual ocorreram 4 eleições presidenciais. Para isso, são utilizados como recursos a revisão bibliográfica e a estatística descritiva. São discutidos textos que trabalham o conceito de representação de modo geral (no tópico 1), assim como os relacionados à representação no contexto brasileiro contemporâneo (apartado 2). Para analisar o caso brasileiro, enfoque principal deste artigo, recorreu-se às pesquisas do ESEB 11 Tomaram-se como referência duas perguntas do survey, a que questiona o entrevistado se existe algum partido que representa seu modo de pensar e a que pergunta se há algum partido de que gosta. É observado, também, se há relação entre o sentimento de representação e as variáveis escolaridade e sexo (parte 3).

Este artigo não tem o objetivo de esgotar ou apresentar conclusões definitivas sobre o tema; pelo contrário, visa, principalmente, a levantar essas importantes questões e sinalizar possíveis linhas de pesquisa a serem desenvolvidas posteriormente.

\section{Debatendo a representação e o papel dos partidos políticos}

O tema da representação tem despertado o interesse de pesquisadores desde a segunda metade do século XX. Desde o clássico trabalho de Pitkin (1967) até as análises mais contem-

\footnotetext{
1 Estudo Eleitoral Brasileiro. O estudo constitui-se de um survey com representatividade nacional realizado em anos de eleições majoritárias no período imediatamente posterior às eleições. Atualmente o estudo conta com 4 rodadas. A primeira foi realizada em 2002 e, em seguida, foram realizadas novas pesquisas em 2006,2010 e 2014.
}

Conexão Política, Teresina v. 6, n. 2, 65-79, jul./dez. 2017 
porâneas como as de Urbinati e Warren (2008), o debate tem girado em torno do papel e da importância da representação nas democracias contemporâneas.

Neste debate, uma das discussões que vem à tona é a que diz respeito ao papel dos partidos políticos e à representação como uma característica importante nas democracias. De acordo com Pitkin (1967), o conceito está relacionado à concepção de representação de ideias, e não à concepção de representação individual, isto é, aquela em que um representante será o porta voz de uma plataforma, de um coletivo, de ideias, não de um interesse particular. Nesse sentido, argumenta-se que um candidato eleito para o parlamento, por exemplo, deve servir a todo país e não somente a seu estado, sua região ou seus eleitores. Assim, o conceito é superior à ideia de individualidade.

De acordo com essa linha de argumentação, as eleições são fundamentais para garantir que os cidadãos possam escolher os partidos que melhor representam seus interesses. Urbinati e Warren (2008) argumenta - valendo-se da teoria política da representação - que a legitimidade do governo advém de sua escolha por meio de eleições livres e regulares. Eleições que promovem uma interação entre a sociedade civil e a política, que são essenciais ao desenvolvimento e à manutenção do regime democrático, e não somente algo inevitável. A autora destaca "a natureza idealizadora e julgadora da política [...], uma arte pela qual os indivíduos transcendem o imediatismo de sua experiência e de seus interesses [...]" (URBINATI, 2000, p. 760).

Os partidos políticos despontam, então, como importantes canalizadores do interesse comum junto ao poder público. Os diferentes partidos, com seus diferentes pontos de vista ou ideologias, seriam os responsáveis por levar ao poder público as demandas das diversas posições encontradas na sociedade (DIAMOND; GUNTHER, 2001). Uma das principais funções dos partidos seria a de atuar como um atalho informacional para a tomada de decisão dos eleitores (DIAMOND; GUNTHER, 2001; KINZO, 2005).

Resumidamente pode-se pensar em três funções dos partidos políticos: a relação com a burocracia partidária, a relação com o poder e a relação com a sociedade. O primeiro tópico está ligado à ideia da administração do partido, sua composição, seleção de candidatos etc. O segundo está relacionado aos aspectos procedimentais, composição de governo, elaboração de políticas públicas etc. Finalmente, o terceiro diz respeito às conexões entre os partidos e a sociedade, seu papel de intermediar.

Como se pode apreender, as três funções são fundamentais em um regime democrático. No primeiro caso, é importante haver um alinhamento interno entre os diferentes setores do partido a fim de que se ofereça à sociedade uma gama de possibilidades de políticas públicas. É necessário, ainda, haver coerência quanto aos princípios norteadores do partido e a seu posicionamento/comportamento quando no governo, estando na situação ou na oposição. Quando se trata dos aspectos procedimentais, os partidos são importantes para garantir a governabilidade e a implementação de políticas públicas, uma vez que no governo terão a possibilidade de manifestar seu posicionamento ideológico propondo e votando políticas públicas. Quando falamos do terceiro aspecto, é fundamental que os partidos estejam sintonizados com a sociedade a fim de traduzir suas demandas junto ao governo e implementar as políticas solicitadas.

Conexão Política, Teresina v. 6, n. 2, 65-79, jul./dez. 2017 
Apesar da importância dessas três funções, as democracias contemporâneas vêm assistindo, nos anos recentes, um esvaziamento da função "relação com a sociedade". Inúmeros estudos têm apontado o enfraquecimento desse papel do partido político. Esse enfraquecimento é perceptível na queda das filiações e da identificação partidária e impacta na capacidade dos partidos de estruturar os votos. Isso seria o resultado da associação de fatores individuais e sistêmicos, de acordo com Dalton et al. (2003) e Paiva, Braga e Pimentel Jr. (2007).

Algumas explicações têm sido levantadas nesse sentido. Uma delas está relacionada às mudanças sociais ocorridas desde o século XX, dentre as quais chamam atenção o papel da mídia e das mídias sociais na construção de interesses, a ascensão dos valores pós-materialistas (DIAMONT; GUNTHER, 2001) e a cartelização dos partidos políticos (KATZ; MAIR, 1995).

O processo que acontece quase de forma simultânea é caracterizado: por um lado, pelo aumento da influência da mídia e pelo protagonismo das redes sociais, que fornecem ao cidadão um modo de se informar que prescinde das organizações previamente existentes. Esses instrumentos têm atuado como importantes formadores de opinião na contemporaneidade. No caso do Brasil, pesquisas recentes (LAZZARI, 2017) analisam em que medida assistir ao Jornal Nacional (telejornal diário de grande alcance no Brasil) influencia os eleitores no que tange à desafeição política, por exemplo.

Por outro lado, o enfraquecimento dos laços dos partidos com a sociedade é relatado quando falamos dos partidos de massa (DUVERGER, 1980), que teriam passado a uma estrutura catch all, ampliando o seu apelo e a sua base eleitoral ao formato de partido cartel, uma estrutura ligada ao governo com poucos vínculos com a sociedade. Essa transformação na estrutura dos partidos leva ao debate acerca da crise dos partidos. De acordo com Mair (2003), devido às mudanças observadas na democracia e na própria sociedade, os partidos têm se conscientizado das dificuldades para atuarem como agentes de representação. Continuam, contudo, exercendo importante função na gestão da democracia.

Nesse sentido, cabe avaliar importantes variáveis que podem sinalizar parâmetros da percepção de representação dos partidos diante do eleitorado. De acordo com pesquisas realizadas em democracias consolidadas, tanto a filiação partidária quanto a participação eleitoral registraram uma queda de pouco mais de 50\% entre os anos de 1980 e 1990 (DIMONT; GUNTHER, 2001). Observando esses dados mais recentemente, é possível notar a tendência de queda nas duas variáveis discutidas. Mair (2013) argumenta que além deste declínio visível, tanto no número de filiados como na participação eleitoral, um fato evidente é que as organizações partidárias têm se mostrado incapazes de atrair as atenções dos eleitores.

\section{Representação no Brasil}

Como uma democracia oriunda da terceira onda (HUNTINGTON, 1994), o Brasil - assim como outros países que vivenciaram regimes de exceção entre os anos 1960 e 1980 - apresenta algumas particularidades. Nesse sentido, é importante destacar que as rupturas empreendidas pelos regimes ditatoriais levaram a uma descontinuidade dos laços existentes entre os partidos e os cidadãos em muitos países. O Brasil é um desses casos.

Conexão Política, Teresina v. 6, n. 2, 65-79, jul./dez. 2017 
O processo de redemocratização constituiu-se como um grande desafio em diferentes aspectos: desde a retomada da institucionalidade, passando pela reconstrução dos marcos legais, até a reestruturação dos canais de interlocução entre o poder público e a cidadania. Isso se deu justamente no momento em que a sociedade atravessava um momento de profundas transformações, tanto no que tange a sua incorporação no sistema político como no que diz respeito à comunicação midiática, à ascensão de valores pós-materialistas e à construção de novas identidades partidárias. Diferentemente das democracias consolidadas nas quais os ciclos ocorreram separadamente $2^{2}$ nas novas democracias ocorreram praticamente de maneira simultânea.

No Brasil, a instituição do multipartidarismo, em 1979, promoveu o surgimento de agremiações que não tinham vínculos com o sistema político no período pré-ditadura. Essas teriam como desafio chegar ao cidadão e firmar-se como intermediador de seus interesses. O único partido que conseguiu capilaridade nacional e identidade com os eleitores foi o PMDB $3^{3}$ Os demais, embora em alguns casos, como o PC do B e o $\mathrm{PTB} 4^{4}$ reivindicassem sua identidade pré-ditadura, constituíam uma novidade no cenário político nacional. Além disso, os inúmeros processos de mudança de nome, fusão e fragmentação de partidos podem ser entendidos como complicadores para a percepção e identificação dos eleitores.

Assim, os problemas, supracitados, observados nas democracias consolidadas, como demonstram Gunther e Diamond (2001), aqui seriam potencializados devido à dificuldade de construção de vínculos entre a identidade do cidadão e a dos partidos. Outro agravante seria o fato de serem raros os casos na história do país de partidos que surgiram a partir das organizações sociais. De acordo com Kinzo (2005), apenas PC do B e o PT constituiriam esse modelo.

Sendo os partidos os intermediadores da relação entre sociedade e poder político, é importante levar em consideração o seu funcionamento e a sua relação com os filiados. Considerando que os eleitores filiados seriam os que apresentam maior interesse na vida partidária, deve-se analisar o comportamento desses eleitores a fim de pensar questões acerca da representação. Como discutido anteriormente, essas questões são sinalizadoras dos vínculos entre eleitores e partidos.

Quando se trata de filiação, no caso brasileiro, os dados podem ser verificados nas pesquisas realizadas pelo ESEB. O artigo de Speck, Braga e Costa (2015) constata não apenas o baixo nível de filiação partidária como a baixa identificação dos próprios filiados. Primeiramente, os autores constatam uma discrepância nos números oficiais de filiados (11\% do eleitorado) e na porcentagem de filiados observados pelo survey (3\%). Sobre essa discrepância, esclarecem que: "Sendo dois universos diferentes, é importante ressaltar que o universo dos filiados do ESEB são aqueles que se auto-identificaram como sendo filiados a um partido político" (SPECK; BRAGA; COSTA, 2015, p. 130). A partir dos dados da pesquisa, os autores constatam que há maior

${ }_{2}^{2}$ Nas democracias consolidadas os partidos já tinham enraizamento social quando acontecem as transformações sociais.

3 Ao acrescentar apenas o P na sigla, o partido que fora a oposição ao regime militar pode manter sua organização territorial, desenvolvida ao longo do período ditatorial, assim como a identificação com o eleitorado.

4 Apesar da tentativa de remeter ao partido antes pré-período ditatorial, o PTB pós-reforma de 1979 era formado por diferentes atores com características distintas ao do partido criado por Vargas em 1945.

Conexão Política, Teresina v. 6, n. 2, 65-79, jul./dez. 2017 
porcentagem de filiação na região Norte $(5,1 \%)$ que no Sudeste $(1,8 \%)$. O estudo aponta, ainda, que as taxas de filiação são maiores quanto menor o município, levando à conclusão de que tanto os processos de filiação quanto os outros tipos de vínculos partidários se associam mais às "relações de proximidade interpessoal do que indica as teorias clássicas de identificação partidária" (SPECK; BRAGA; COSTA, 2015, p. 144).

Importante, também, chamar a atenção para uma das conclusões dos autores que constata que um em cada quatro filiados não gosta de nenhum partido (21\%) e que $29 \%$ destes gostam de outro partido, ou seja, estão filiados em um partido que não é da sua preferência. Para os autores, isto "significa que não podemos avaliar toda filiação como expressão de um compromisso mais intenso com certo partido" (SPECK; BRAGA; COSTA, 2015, p. 145).

Partindo para uma observação do eleitorado, em geral é possível avaliar a desconfiança dos eleitores em relação aos partidos políticos, atores que, como mencionado anteriormente, seriam responsáveis por captar os interesses dos cidadãos e intermediar suas relações com o poder público. Em seu estudo a partir dos dados do Survey Brasil 25 anos de democracia, Lazzari (2017) analisa a existência de um problema de confiança nos partidos políticos, que não estaria associado a características socioeconômicas, tais como gênero, renda, escolaridade e idade. De acordo com o autor, a desconfiança é generalizada. Ainda de acordo com o autor, "[...] avaliar que a corrupção aumentou ou piorou engendra uma maior desconfiança em partidos" (LAZZARI, 2017, p. 353).

Lazzari (2017) conclui que aparentemente não é possível afirmar que as variáveis escolhidas afetam a desconfiança. O fenômeno é observado em todos os estratos. O autor constata, também, que não há associação entre o crescimento da desconfiança e a redução da confiança, ou seja, não há indicações de que as duas variáveis estejam associadas de maneira determinística. Contudo, ele defende que

[...] essas categorias não são independentes entre si, mas seus comportamentos diferentes ante os fatores que as impactam, em que a confiança terá um espaço muito menor para crescer, indicam um tipo de antipartidarismo cultural, mais profundo na sociedade, em que sua reprodução é ritualizada, enquanto a desconfiança remeteria a um antipartidarismo reativo.

A percepção do eleitorado, ainda de acordo com Lazzari (2017), é que os partidos não levam em conta os interesses dos cidadãos, ou seja, os interesses dos representados, mas que esses atores têm agido de forma independente, buscando principalmente seus próprios interesses. Essa constatação do autor confirmaria a hipótese de fragilização dos vínculos do partido com a sociedade e seu comprometimento apenas com a permanência no governo. Nesse ponto cabe retomar o debate acerca do mandato e da independência, que pode ser resumido na escolha entre o representante fazer o que ele acha melhor ou o que os eleitores querem que ele faça. Voltamos aqui ao debate acerca do significado da representação. Pitkin (1967) vai chamar a atenção para o fato de que a representação significa tornar presente algo que não está presente de fato. De fato, quando tratamos do conceito no contexto político, uma série de considerações deve ser feita. Pitkin (2006, p. 30) argumenta que

Conexão Política, Teresina v. 6, n. 2, 65-79, jul./dez. 2017 
[...] paradoxo é recoberto por várias preocupações substantivas: a relação entre os representantes na legislatura, o papel dos partidos políticos, na medida em que os interesses locais e parciais se encaixam no bem nacional, a forma pela qual a deliberação se relaciona com o voto e ambas se relacionam com o exercício do governo etc.

A autora defende, ainda, que, uma vez que a relação de cada parlamentar é com a nação, na verdade não existe um vínculo especial com o seu eleitorado. Essa seria uma das vantagens da representação. Uma vez eleito, embora comprometido com seu programa político, o candidato representaria a nação como um todo, não interesses privados.

\section{A percepção da representação no Brasil contemporâneo}

Após essa breve análise da literatura sobre representação, filiação partidária e desafeição política, é importante discutir as razões desse afastamento e da descrença dos eleitores nos partidos políticos, assim como pensar no papel dos partidos como estruturantes do voto no contexto brasileiro.

Paiva, Braga e Pimentel Jr. (2007) analisam o papel dos partidos na formação das preferências eleitorais e na estruturação do voto. Os autores discutem a preferência partidária, o grau de representatividade dos partidos, o conhecimento dos partidos e a confiança nos mesmos. Os autores concluem que não se pode afirmar satisfatoriamente a avaliação dos partidos no âmbito da representação. Eles argumentam que:

Na medida em que os partidos políticos são instituições cruciais para o funcionamento da democracia representativa, os laços pouco estáveis entre partidos e o eleitorado aqui verificados e a baixa confiança depositada naqueles, levam a ver com preocupação seu impacto a médio prazo para a legitimidade da ordem democrática (PAIVA; BRAGA; PIMENTEL JR., 2007, p. 405).

A partir dos dados do ESEB 2002, 2006, 2010 e 2014, é possível observar se os brasileiros se sentem representados pelos partidos políticos e se é possível notar mudanças nessa percepção ao longo do tempo. Analisa-se, também, se variáveis como sexo e escolaridade diferenciam a percepção de representação dos partidos.

A primeira questão a ser analisada é relacionada ao sentimento de representação. Quando questionados se algum partido representa a maneira que pensam, é possível notar que menos de 40\% responderam afirmativamente, sendo que os anos de 2002 e 2010 foram os que tiveram mais respostas afirmativas, com cerca de 39\%. Como pode ser observado no Gráfico 1, 2006 e 2014 foram os anos que apresentaram mais respostas negativas. Aproximadamente $67 \%$ dos entrevistados consideram que nenhum partido representa sua maneira de pensar.

Quanto ao que se observa nos dados, é importante chamar a atenção para o contexto brasileiro no período analisado. Cabe considerar o impacto que fatores de ordem política, econômica e social exercem sobre a percepção dos cidadãos. Na literatura de Ciência Política, 
Gráfico 1- Algum partido representa a maneira de pensar

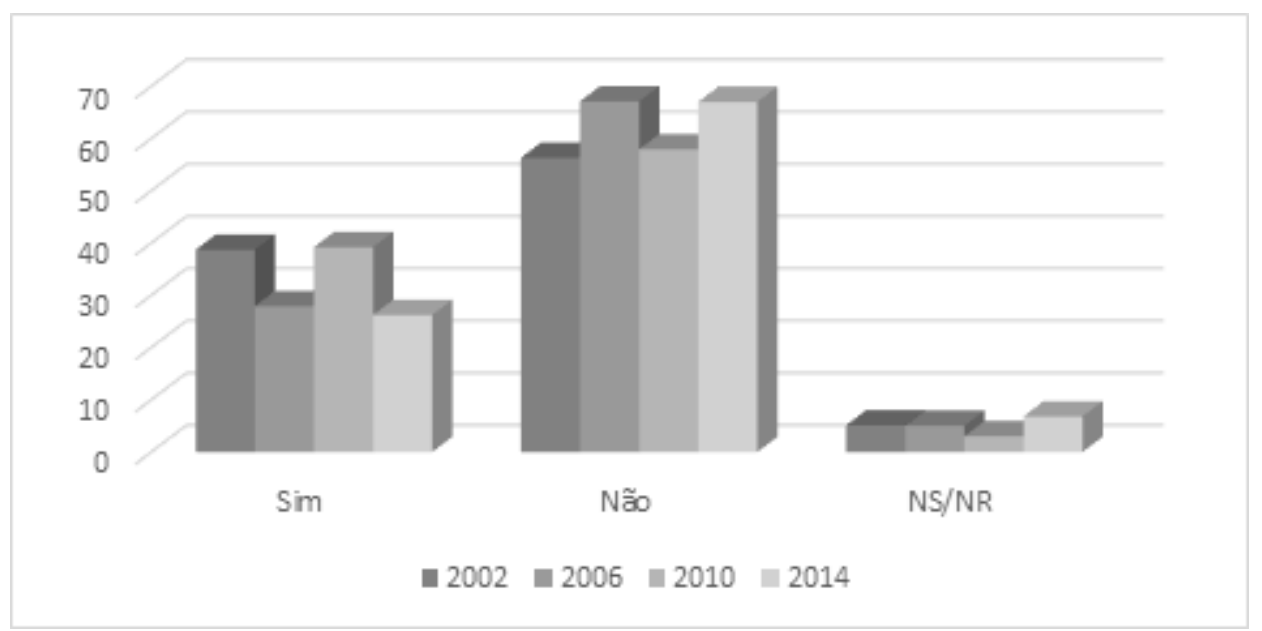

Fonte: Elaborado pelo autor a partir de dados do ESEB 2002, 2006, 2010 e 2014.

existe um grande debate acerca da avaliação que os eleitores fazem do desempenho do governo, especialmente no que tange às questões econômicas. Uma constatação dessa literatura é que a economia impacta nas eleições. Carreirao (1999) analisa como a economia exerceu influência nas escolhas eleitorais brasileiras nos anos 1980 e 1990. Pereira (2014) segue linha semelhante ao avaliar o voto nas eleições presidenciais de 2002. A partir de análises do voto econômico, verifica-se como as escolhas dos eleitores são influenciadas por fatores contextuais - nestes casos, pela economia.

Assim como a economia, fatores de ordem política e social influenciam a percepção dos eleitores. Pode-se citar, por exemplo, a avaliação do governo Dilma antes e depois das manifestações de 2013. De acordo com as pesquisas Datafolha, a avaliação positiva do governo da então presidenta caiu 27 pontos em três semanas, justamente no período das manifestações $:^{5}$ Poucos meses antes do fenômeno, a avaliação positiva da presidenta havia alcançado níveis records, de acordo com pesquisas do IBOPE.

Sob esse ponto de vista, cabe mencionar que em 2002 houve uma grande expectativa com a chegada do PT ao governo. O partido despontava como a possível solução dos problemas que o país enfrentara durante o segundo mandato do presidente Fernando Henrique Cardoso. Tal expectativa pode ter influenciado o sentimento de representação dos cidadãos. Por outro lado, a eleição de 2006 ocorreu em um clima de desgaste do governo do presidente Luiz Inácio Lula da Silva, principalmente devido aos escândalos de corrupção de pessoas importantes do PT ou ligadas ao governo. A eleição de 2010 ocorreu novamente em clima de expectativas. A economia apresentava sinais positivos e se esperava que o crescimento continuasse. A eleição de 2014, por sua vez, acontece após um turbilhão de problemas, tanto de ordem econômica como de ordem política e social (pós-manifestações de 2013, queda da popularidade da presidente etc.). Pode-se pensar que a avaliação do governo exerce influência na percepção da representação. Observa-se que daí desponta uma agenda de pesquisas que exigiria maior esforço e análise da

\footnotetext{
5 Aa manifestações de 2013 se iniciaram como reivindicação contra o aumento no preço do transporte público e incorporaram uma série de demandas por políticas públicas tais como a saúde e educação, e agregou, também, a insatisfação com a corrupção. O movimento teve grande repercussão e teve como característica a rejeição aos partidos políticos.
}

Conexão Política, Teresina v. 6, n. 2, 65-79, jul./dez. 2017 
relação entre avaliação do governo, desempenho econômico e sentimento de representação, tema esse que se pretende analisar com maior profundidade em trabalhos futuros.

Gráfico 2 - Partido que gosta, em 2002, 2006, 2010 e 2014

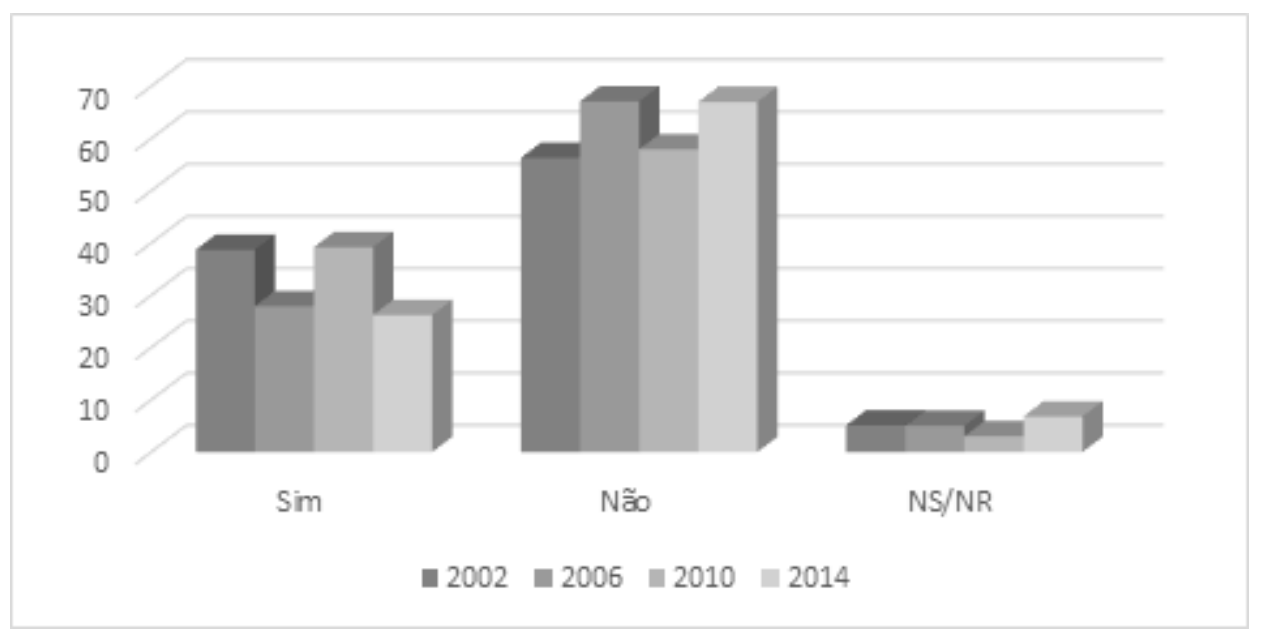

Fonte: Elaborado pelo autor a partir de dados do ESEB 2002, 2006, 2010 e 2014.

Assim como no caso de haver algum partido que representa a maneira de pensar, os dados referentes a "gostar de um partido", Gráfico 2, apresentam mais respostas afirmativas nos anos de 2002 e 2010, com cerca de 48\% dos respondentes nos dois anos. Já nos anos de 2006 e 2014, as respostas negativas são superiores aos demais anos observados, com 63\%. Nesse sentido, assim como no caso dos dados acerca da representação, é possível inferir que os contextos político e econômico podem ter impactado na percepção e no sentimento dos eleitores.

No Quadro 1, busca-se analisar a relação entre gostar de um partido e se sentir representado. A hipótese é que aqueles que se sentem representados gostem de algum partido; o contrário não se verificaria uma vez que o partido que tem o afeto do eleitor pode não ter representação no governo, o que levaria o eleitor a não se sentir representado.

Tabela 1- Partido que gosta X Partido que representa

\begin{tabular}{|c|c|c|c|c|c|c|c|c|c|}
\hline & \multicolumn{9}{|c|}{ Algum partido de que gosta } \\
\hline \multirow{4}{*}{$\begin{array}{l}\text { Algum partido } \\
\text { representa sua } \\
\text { maneira de pensar }\end{array}$} & \multirow[t]{2}{*}{ Ano } & \multicolumn{2}{|c|}{2002} & \multicolumn{2}{|c|}{2006} & \multicolumn{2}{|c|}{2010} & \multicolumn{2}{|c|}{2014} \\
\hline & & Não & Sim & Não & Sim & Não & Sim & Não & Sim \\
\hline & Não & $71,5 \%$ & $28,5 \%$ & $86,0 \%$ & $12,5 \%$ & $85,2 \%$ & $14,5 \%$ & $85,8 \%$ & $13,4 \%$ \\
\hline & Sim & $19,7 \%$ & $80,3 \%$ & $15,4 \%$ & $84,2 \%$ & $23,0 \%$ & $76,1 \%$ & $13,6 \%$ & $84,5 \%$ \\
\hline
\end{tabular}

Fonte: Elaborada pelo autor a partir de dados do ESEB 2002, 2006, 2010 e 2014

De acordo com a Tabela 1, podemos perceber que há uma discrepância entre gostar e se sentir representado. Em média, 17\% dos entrevistados que gostam de um partido não se sentem representados por nenhuma agremiação. 2002 apresenta o maior percentual de entrevistados que gostam de algum partido, mas não se sentem representados por nenhum (28,5\%). O ano que apresenta o menor percentual é 2006, com 12,5\%. Por outro lado, em média $18 \%$ dos entrevistados que se sentem representados por algum partido não gostam de nenhum deles, sendo o ano de 2010 o que apresenta o maior percentual de pessoas que se sentem representadas por um partido, embora não gostem de nenhum, e 2014 o ano que apresenta o menor percentual. 
Os dados levam a pensar em algumas hipóteses. Pode-se inferir que, embora gostem de determinado partido, os eleitores analisam de maneira cautelosa o comportamento deste, concluindo que, apesar da simpatia, não conseguem representá-los. Nesse ponto, podemos retomar as reflexões da literatura, expostas anteriormente, quando se analisa o distanciamento do partido do eleitorado. Uma vez que ocorre tal distanciamento, os eleitores, apesar de terem algum vínculo afetivo com o partido, não o veem como seu representante. Não obstante, ao contrário do que se poderia imaginar, o percentual dos que se sentem assim diminui significativamente entre 2002 e 2006: mais de 50\%, com um leve aumento entre 2006 e 2010 e uma leve queda entre 2010 e 2014.

Quando se observa a discrepância entre se sentir representado e não gostar de nenhum partido, alguns questionamentos podem surgir, mas a hipótese que pode ser pensada é que com o bombardeamento de informações negativas acerca dos partidos, aliado às práticas ilícitas e seu afastamento da sociedade produzem esse tipo de posicionamentos. Diferentemente do observado nos dados relativos aos que gostam de algum partido, mas não se sentem representados, no caso contrário não há um padrão. Há uma leve queda dos que se sentem representados, mas não gostam de nenhum partido de 2002 e 2006 (de 17,7 para 15,4). Há, contudo, um considerável aumento nos percentuais entre 2006 e 2010 (chegando a 23\%), seguido de nova queda em 2014 (13,6\%). Seria interessante analisar melhor esses dados à luz do contexto sócio-político e econômico, a fim de verificar os elementos que influenciam essas variações.

Ao analisar a relação entre sexo e representação e escolaridade e representação, tomamos apenas os dados de 2006, 2010 e 2014, uma vez que o survey de 2002 não incluiu questões acerca do sexo ou da escolaridade dos entrevistados.

Gráfico 3 - Sentimento de representação por sexo

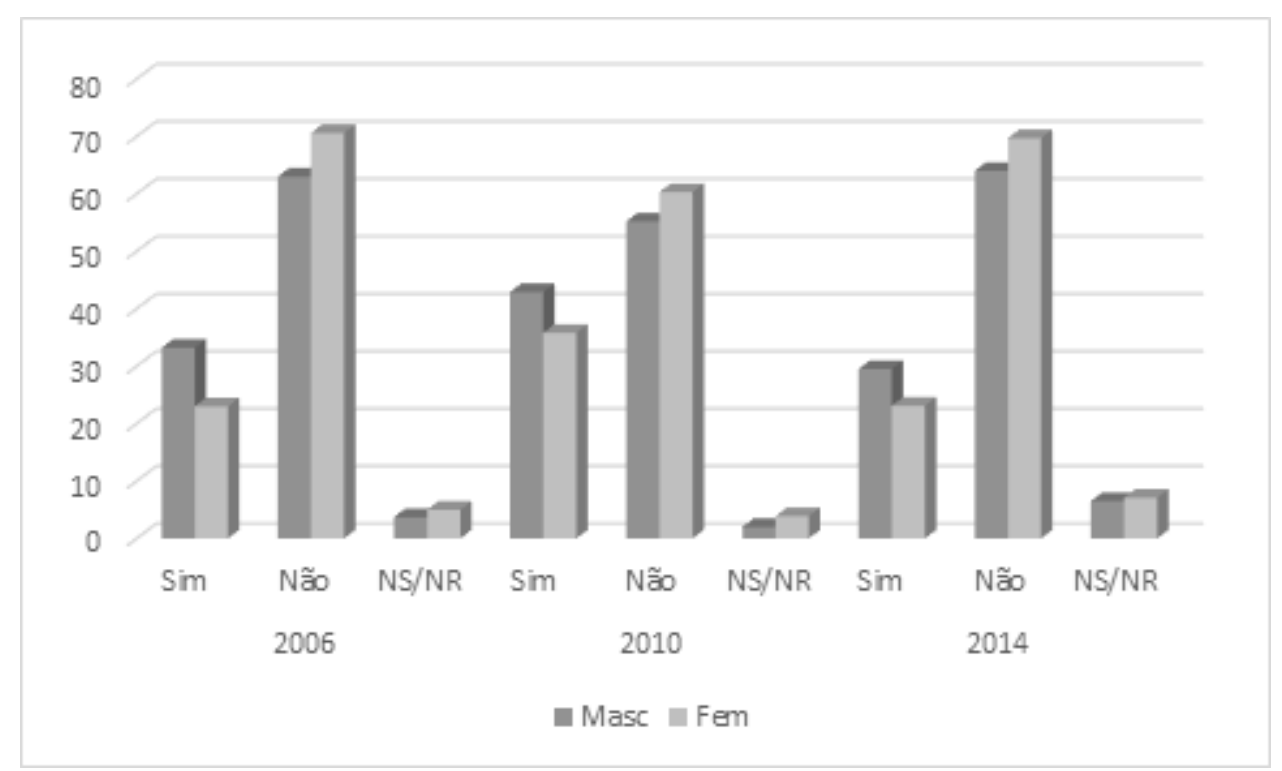

Fonte: Elaborado pelo autor a partir de dados do ESEB 2006, 2010 e 2014.

Quando observamos a percepção de representação por sexo, Gráfico 3, notamos que os homens, em todas as rodadas, sentem-se mais representados que as mulheres. Esses dados também nos levam a pensar algumas hipóteses que podem ser melhor exploradas a fim de ser

Conexão Política, Teresina v. 6, n. 2, 65-79, jul./dez. 2017 
analisadas, dentre elas o fato de as mulheres ainda estarem afastadas da política e de haver poucas nos cargos públicos. Mesmo nas eleições de 2010 e 2014, quando houve uma candidata à presidência da República com reais chances de vitória, o número de mulheres que consideraram que havia um partido que representava sua forma de pensar foi inferior ao percentual de homens.

De acordo com dados do IBGE, as mulheres representam 51,5\% do eleitorado brasileiro e 51,7\% dos votantes. Não obstante, em 2010, ocupavam apenas 9\% das cadeiras na Câmara dos Deputados e 13\% no Senado. Os dados da União Interparlamentar - IPU, de 2013, apontam o Brasil na $156^{\mathrm{a}}$ posição em representação feminina, em uma lista de 188 países. Na América Latina, o país se posiciona no $30^{\circ}$ lugar entre os 34 que formam a região (PROCURADORIA ESPECIAL DA MULHER, 2014). Os dados mostram a discrepância existente entre o total de mulheres no país e sua participação política, o que pode promover a falta de sentimento de representação.

Gráfico 4 - Representação x Escolaridade 2006

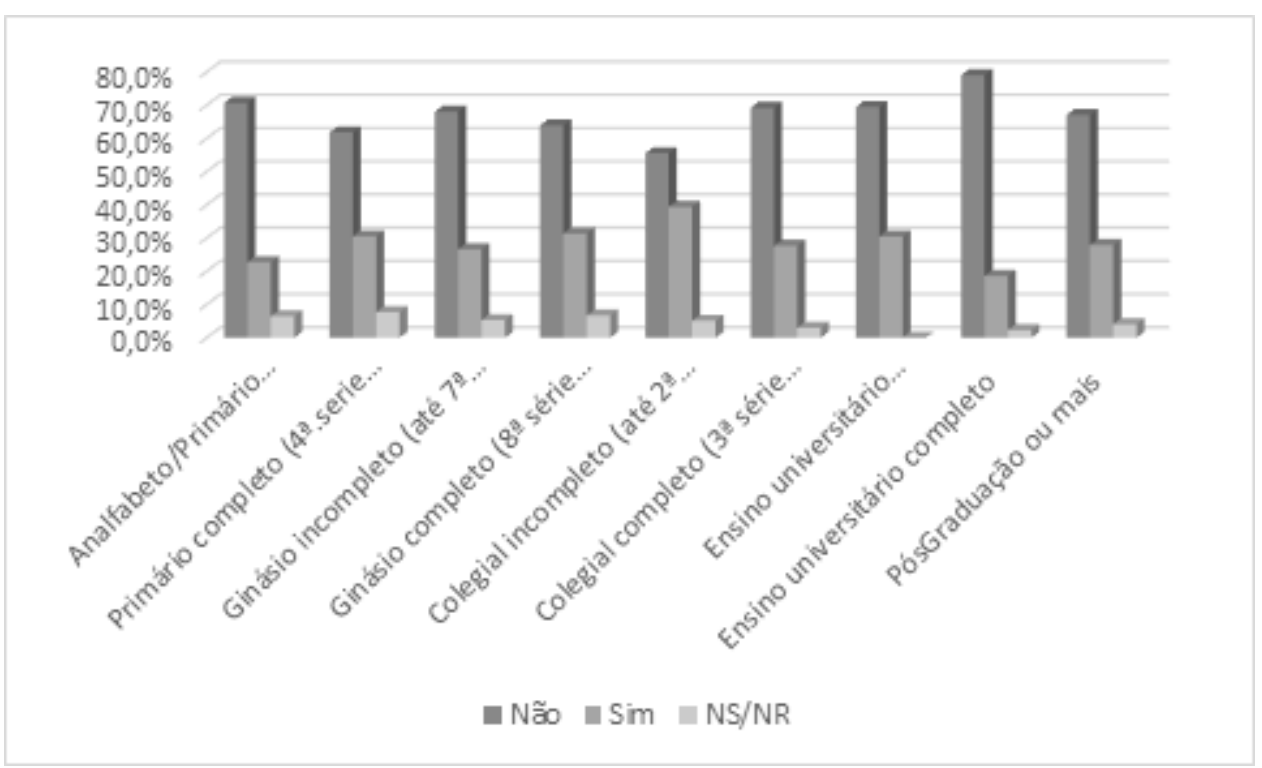

Fonte: Elaborado pelo autor a partir de dados do ESEB 2006, 2010 e 2014.

Quando falamos de escolaridade - gráficos 4, 5 e 6 -, notamos que há pouca variação entre as diferentes faixas e a percepção de representação. Os que se sentem menos representados em 2006 são os com primário incompleto; os que se sentem mais representados são os com colegial incompleto. A diferença é de 15,1 pontos percentuais. Em 2010, os com ensino universitário completo são os que se sentem menos representados, e os que se sentem mais representados são os com pós-graduação. Em 2014, os que se sentem menos representados são, novamente, os com ensino universitário incompleto, e os que se sentem mais representados são os com pós-graduação ou mais.

A partir dos dados, podemos constatar que não há uma relação direta entre escolaridade e sentimento de representação. A princípio, poderia se pensar que os mais escolarizados se sentem mais representados por terem mais acesso à informação ou que aconteceria o contrário, os menos escolarizados se sentindo mais representados. Contudo, os dados não mostram isso. Há uma porcentagem bastante próxima dos que se sentem e dos que não se sentem representados, 
Gráfico 5 - Representação x Escolaridade 2010

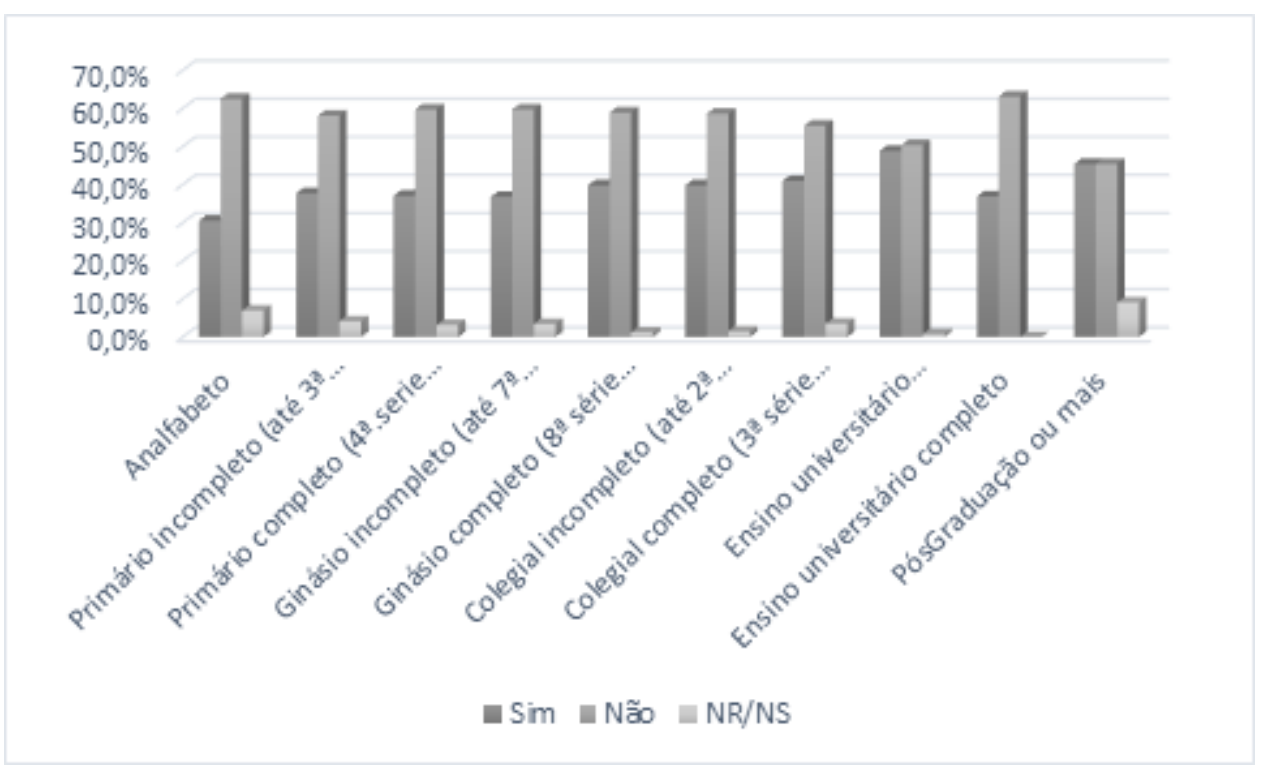

Fonte: Elaborado pelo autor a partir de dados do ESEB 2006, 2010 e 2014.

Gráfico 6 - Representação x Escolaridade 2014

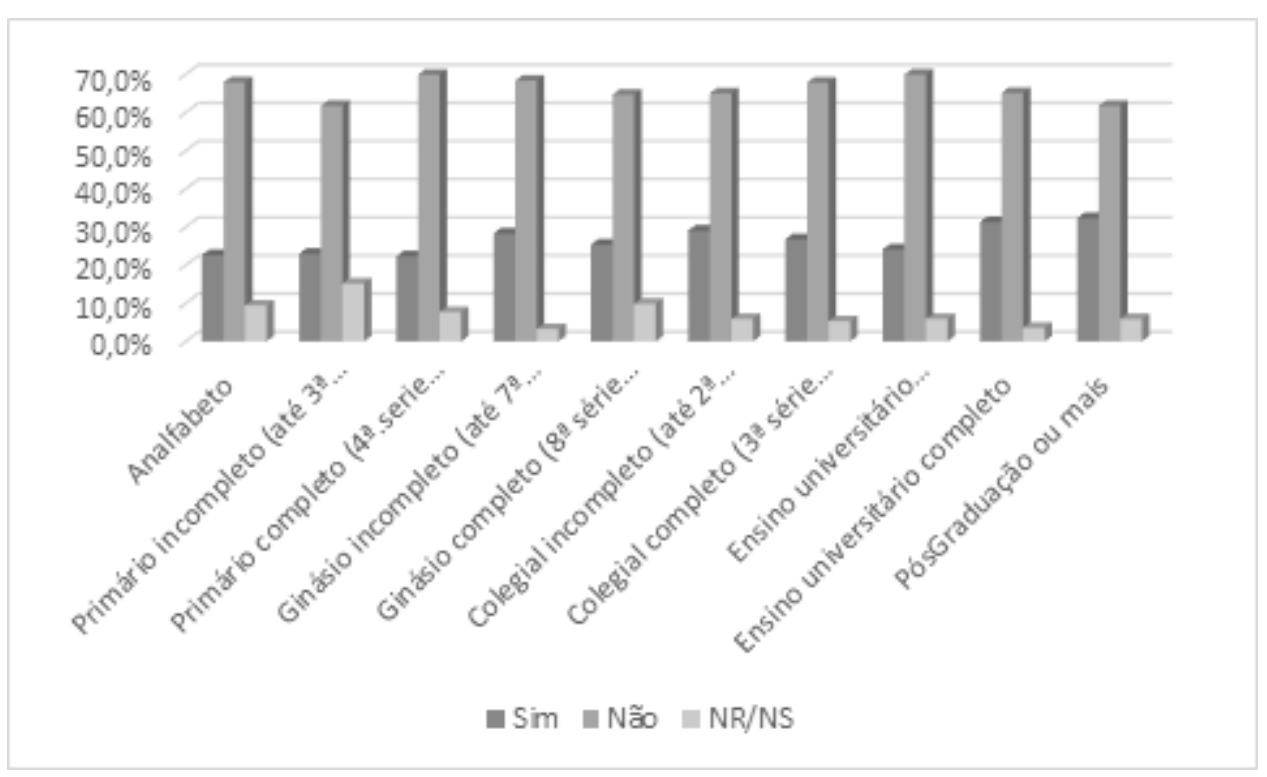

Fonte: Elaborado pelo autor a partir de dados do ESEB 2006, 2010 e 2014

independente da escolaridade. A pequena variação observada foi ao longo do tempo.

\section{Considerações finais}

O debate acerca da representação política constitui um importante tema a ser explorado pela Ciência Política, especialmente dado seu papel na estabilidade democrática. Diante dos desafios contemporâneos, cabe analisar mais detidamente como as democracias contemporâneas têm enfrentado a questão. Apesar de todos os problemas e limitações observados, a representação política ainda desponta como a principal maneira de garantir uma democracia inclusiva, uma vez que, de acordo com a literatura, quando se fala em representação se busca o bem geral e não os interesses privados.

Conexão Política, Teresina v. 6, n. 2, 65-79, jul./dez. 2017 
Muitos dilemas têm emergido, e um dos principais é como tornar a democracia realmente representativa, principalmente em um contexto de afastamento dos partidos políticos da sociedade, crise de legitimidade e representação desses importantes atores políticos, como discutido anteriormente. A literatura demonstra alguns dos dilemas que os partidos políticos vêm enfrentando no contexto contemporâneo, tais como a queda no número de filiados e as altas taxas de abstenção eleitoral.

No caso brasileiro, as pesquisas do ESEB colhem a opinião dos eleitores sobre diferentes aspectos da política, entre eles sobre a representação. Duas das perguntas do survey foram exploradas neste artigo, a que questiona os entrevistados se se sentem representados por algum partido político e se gostam de algum partido. Buscou-se também verificar se essa percepção pode ser associada às variáveis sexo e escolaridade.

Como dito na introdução, este artigo não visa a esgotar o tema, mas, principalmente, apontar questões relevantes que poderão ser investigadas mais a fundo no futuro, sinalizar uma agenda de pesquisa acerca da percepção de representação no Brasil. Uma das considerações que pode ser feita com relação a isso é que se faz mister analisar os dados encontrados à luz do contexto no qual cada um dos surveys foi realizado.

Os dados permitiram observar que há uma baixa percepção de representação por parte dos brasileiros, assim como um percentual considerável de entrevistados que afirmaram não gostar de nenhum partido. Os anos de 2002 e 2006 apresentam maior proporção de eleitores que responderam negativamente às duas questões. Quando se efetuou o cruzamento das duas variáveis, notou-se que cerca de $17 \%$ dos eleitores, embora gostem de algum partido, sentem que nenhum deles representa sua maneira de pensar, enquanto cerca de 18\%, apesar de sentirem que um partido representa sua maneira de pensar, não gostam de nenhum deles.

Quando falamos da percepção da representação por sexo, os dados apontam que as mulheres se sentem menos representadas que os homens. Esse achado sinaliza para a importância de se analisar melhor as questões relativas à inserção feminina na política. Como discutido brevemente, embora seja cerca de $50 \%$ da população, a representação política feminina no Brasil está aquém do esperado. O país desponta como um dos casos em que essa representação é menos efetiva, quando comparado com outras democracias. Nesse sentido, é importante que se desenvolvam estudos a fim de problematizar a questão de como melhorar a representatividade feminina no Brasil.

Como apontado anteriormente, vale investigar mais detidamente como as variáveis contextuais, tais como as econômicas, sociais e políticas, impactam a percepção dos eleitores. Neste trabalho, buscou-se levantar algumas questões que podem sinalizar o caminho para análises mais aprofundadas.

Importante chamar a atenção para as questões relativas à representação política e às políticas públicas. Não se pode deixar de considerar que, enquanto atores de intermediação, os partidos políticos seriam responsáveis por levar as demandas dos cidadãos ao poder público. O sistema representativo permitiria que diferentes demandas fossem levantadas e políticas públicas fossem criadas para atendê-las, contemplando os diferentes setores da sociedade. Pensar na não representação significa inferir que, ao invés de políticas que contemplem as diferentes

Conexão Política, Teresina v. 6, n. 2, 65-79, jul./dez. 2017 
demandas, estão sendo priorizadas políticas localizadas e privadas, algo que feriria o princípio da democracia.

Os dados que têm sido observados na contemporaneidade sinalizam para a necessidade urgente de se pensar a representação e de se pensar como os atores políticos podem chegar ao eleitor e agir como seu intermediador mediante o sistema político.

\section{Referências}

CARREIRAO, Y. de S. Avaliação do governo e "voto econômico". Lua Nova, São Paulo, n. 48, p. 213-232, dez. 1999.

DUVERGER, M. Os partidos Políticos. 2. ed. Rio de Janeiro: Zahar; Brasília: UNB, 1980.

DIAmOnd, L.; GUNTHER, R. (Ed). Political Parties and Democracy. Baltimore: Johns Hopkins University Press, 2001.

HUNTINGTON, S. A terceira onda: a democratização no final do século XX. São Paulo: Ática, 1994.

KATZ, R.; MAIR, P. Changing models of party organization and party democracy: the emergence of the cartel party. Sage Journals, v. 1, issue 1, p. 5-28, 1995.

KINZO, M. D. Os partidos no eleitorado: percepções públicas e laços partidários no Brasil. $R B C S$, v. 20, n. 57, 2005.

LAZZARI, E. A. Explicações assimétricas para a desconfiança em partidos políticos no Brasil. Opinião Pública, Campinas, v. 23, n. 2, p. 334-360, maio/ago. 2017.

MAIR, P. Os partidos políticos e a democracia. Análise Social, Lisboa, v. 167, p. 277-93, 2003. Ruling the void: the hollowing of western democracy. London-New York: Verso, 2013.

PAIVA, D.; BRAGA, M. do S.; PIMENTEL JR., J. T. P. Eleitorado e partidos políticos no Brasil. Opinião Pública, Campinas, v. 13, n. 2, p. 388-408, nov. 2007.

PEREIRA, F. B. Voto econômico retrospectivo e sofisticação política na eleição presidencial de 2002. Rev. Sociol. Polit. [online], v. 22, n. 50, p. 149-174, 2014.

PITKIN, H. F. The concept of representation. Berkeley; Los Angeles; London: University of California Press, 1967.

Representação: palavras, instituições e ideias. Lua Nova, São Paulo, n. 67, p. 15-47, 2006.

PROCURADORIA ESPECIAL DA MULHER. + Mulher na política: mulher, tome partido! Brasília: Senado Federal, 2014.

Conexão Política, Teresina v. 6, n. 2, 65-79, jul./dez. 2017 
SPECK, Bruno Wilhelm; BRAGA, Maria do Socorro Sousa; COSTA, Valeriano. "Estudo exploratório sobre filiação e identificação partidária no Brasil". Rev. Sociol. Polit., Curitiba, v. 23, n. 56, p. 125-148, dez. 2015.

URBINATI, Nadia. Representation as advocacy: a study of democratic deliberation. Political Theory, Thousand Oaks, v. 28, n. 6, p. 758-786, 2000.

; WARREN, M. E. The concept of representation in contemporary democratic theory. Annual Review of Political Science, Palo Alto, v. 11, p. 387-412, 2008. 